\title{
PEMANFAATAN ELECTRONIC BANKING BAGI ANGGOTA DI KSPPS BMT BINA UMMAT SEJAHTERA CABANG TAYU
}

\author{
Farida Fadlliatul Husna1, Muhamad Mustaqim², \\ ${ }^{2}$ Institut Agama Islam Negeri Kudus \\ $\triangle$ muhamadmustaqim10@gmail.com
}

\begin{abstract}
: This paper aims to examine the utilization of electronic banking for members in KSPPS BMT Bina Ummat Sejahtera (BUS) Tayu Branch, as well as the factors that influence it. This research is included in field research with qualitative approach. The results showed that the utilization of electronic banking in BMT Bina Ummat Sejahtera is currently not fully carried out. Some members still do not use electronic banking, for several reasons such as: limited facilities, perceptiveness about e-banking that impresses, complicated, and worries about security risks. Meanwhile, factors that influence the utilization of ebanking include: member interest, desire to use, perception that includes: perception of trust, ease, and risk perception. The results of this study provide an idea that it is necessary to socialize and educate the use of e-banking, especially for the lower middle class, and rural areas.
\end{abstract}

Keywords $\quad$ : E-Banking, ATM, Sharia Cooperatives

\section{LATAR BELAKANG}

Perkembangan teknologi informasi saat ini, telah menciptakan jenis-jenis dan peluang-peluang bisnis yang baru, dimana transaksi-transaksi bisnis makin banyak dilakukan secara elektronika. Sehubungan dengan perkembangan teknologi informasi tersebut memungkinkan setiap orang dengan mudah melakukan transaksi. Perkembangan internet memang cepat dan memberikan pengaruh siginifikan dalam segala aspek kehidupan kita (Yustiawan, 2019).

Perbankan memberikan kemudahan bagi nasabah/anggota melalui electronic banking. Untuk melakukan layanan operasional tersebut ada electronic banking yang berjenis delivery channel yang sangat umum (seperti ATM) maupun dengan jenis delivery channel yang lainnya seperti SMS Banking, Telephone Banking, Internet Banking, EDC (Electronic Data Capture) dan lain sebagainya. Dengan adanya electronic banking masyarakat dapat melakukan transaksi tidak hanya melulu dengan menggunakan uang tunai, karena sekarang sudah ada layanan perbankan modern yang lebih efektif dan efisien untuk digunakan (Jasmi, 2015).

Pada lima tahun terakhir ini, perkembangan ponsel pintar sangatlah pesat. Pata tahun 2014 teercatat angka 19\%, meningkat cukup pesat pada tahun 2018 sebesar 56 $\%$. Hal ini berdampak positif terhadap nasabah bank dan juga pengguna internet dan mobile banking.

Tingkat mobilitas di masyarakat yang semakin meningkat dari tahun ke tahun menyebabkan para penyedia layanan bagi masyarakat seperti perbankan melakukan banyak inovasi dan peningkatan kemudian pelayanan. Internet tidak hanya digunakan untuk menemukan informasi melalui media, akan tetapi juga dapat digunakan untuk 
melakukan transaksi perbankan. Bank Indonesia sudah mengembangkan fasilitasi di dunia maya, yani melalui internet banking yang merupakan salah satu produk dari ebanking (Hambali, dkk., 2014).

E-Banking pada dasarnya merupakan kontak suatu transaksi perbankan antara pihak bank dan nasabah dengan menggunakan media internet dan media elektronik, hal ini yang membuat bank untuk berlomba-lomba meluncurkan produk-produk layanan e-banking. Teknologi informasi seperti e-banking sekarang ini digunakan sebagai alat penunjang untuk maju dan berkembangnya bagi pelayanan jasa perbankan (Pinontoan, 2013).

Melalui e-banking tersebut pihak perbankan memberikan layanan yang cepat, mudah, nyaman, aman, bertransaksi selama 24 jam, dan dapat diakses di mana saja dan kapan saja. Dengan adanya layanan mobile banking tersebut, dapat memudahkan kita untuk memeriksa saldo rekening, memonitor jangka waktu deposito, mengecek status kartu kredit, pembayaran rekening listrik, telepon dan transaksi lainnya akan lebih mudah dilakukan. Akan tetapi, meskipun kualitas teknis sistem teknologi informasi sudah menigkat, masih saja banyak yang mengalami kegagalan dalam penerapannya. Hal ini dipengaruhi oleh beberapa faktor, salah satunya karena nasabah/anggota sudah merasa nyaman dengan layanan yang sudah ada.

Beberapa riset telah dilaukan terkait dengan pemanfaatan internet banking ini. Mulidiyah dan Setyawan (2017) meneliti tentang persepsi kemudahan penggunaan dan kesesuaian dalam menggunakan mobile banking pada Bank Mandiri di Surabaya. Hasil penelitian menunjukkan bahwa persepsi manfaat memberikan pengaruh yang signifikan terhadap nasabah dalam menggunakan mobile banking. Demikian juga dengan kajian Arthana dan Rukhviyanti (2015), Laksana, dkk. (2015) serta Kharismawan dan Widiyanto (2016) yang amsing-masing meneliti tentang pemancaatan internet maupun mobile banking dengan pendekatan kuantitatif.

Artikel ini hendak membahas tentang pemanfaatan electronic banking bagi anggota di KSPPS BMT Bina Ummat Sejahtera cabang Tayu, serta faktor-faktor yang mempengaruhinya dengan melalui pendekatan kulaitiatif.

\section{TEORI DAN METODE}

\subsection{Electronic Banking}

Pertumbuhan electronic banking atau internet banking yang didukung dengan perkembangan teknologi, media sosial dan pola hidup masyarakat memberikan manfaat bagi industri perbankan. Hal ini secara nyata dapat menghasilkan pendapatan fee based income, bias mengurangi biaya transaksi, mampu mengembangkan bisnis serta mampu meningkatkan kepercayaan atau loyalitas nasabah maupun anggotanya. Penggunaan e-banking ini, memberikan kenyamanan dan kemudahan dalam melaukan transaksi secara bebas, tidak terbatas oleh waktu dan lokasi (Jasmi, 2015).

Tujuan dari pemanfaatan electronic banking bagi nasabah/anggota dan pengawas bank adalah untuk memberikan pemahaman yang komprehensif, maupun memberikan edukasi oleh bank untuk mendukung penggunaan electronic banking sebagai alat dan perangkat transaksi oleh para nasabah atau anggota.

Selain itu, pemanfaatan teknologi electronic banking juga memberi beberapa manfaat, seperti: mobilitas, model pelayanan yang berubah dimana nasabah atau anggota tidak perlu datang ke kantor cabang bank, pembayaran menjadi lebih mudah 
serta pelayanan bias dilaukan kapan saja, tidak mengenal waktu dan tempat (Joyosumarto, 2018) .

Perkembangan transaksi electronic banking saat ini sudah mampu melakukan banyak hal, tetapi masih akan dapat berkembang lebih jauh lagi pada masa yang akan dating. Saat ini transaksi yang dapat dilakukan antara lain: pengecekan Saldo, transfer uang, pembayaran tagihan, informasi rekening, serta pemindahbukuan (Lestari, 2019).

\section{a. Produk Electronic Banking}

Kemajuan teknologi electronic banking sangat pesat melalui interkoneksi komunikasi dan melalui jaringan wireless (tanpa kabel). Penggunaan internet dan teknologi mutakhir saat ini telah menjadikan e-banking mampu melahirkan beberapa produk, yaitu; ATM, EDC, internet banking, sms banking, mobile banking, electronic commerce, phone banking, dan video banking (Jasmi, 2015).

\section{b. Keamanan Transaksi Electronic Banking}

Keamanan adalah hal yang paling utama pada penggunaan electronic banking, karena dengan adanya transaksi perbankan melalui internet akan rawan dengan penyalahgunaan dan tindakan yang tidak bertanggung jawab. Sebuah situs $e$-banking diwajibkan untuk menggunakan strandar keamanan yang sangat ketat (Juanda, 2018). Berikut adalah kemanan yang dapat dilakukan untuk bertransaksi melalui $e$-banking:

1). PIN merupakan kode akses sehingga nomor PIN merupakan kode rahasia pribadi, tidak boleh orang lain mengetahuinya.

2). User ID dan key token yang harus dijaga kerahasiaannya.

3). Mengganti nomor PIN secara berkala.

4). Untuk menggunakan phone banking SIM Card Handphone harus terdaftar pada data base komputer bank. Apabila hal tersebut sudah tidak digunakan maka harus di unregistered.

5). Nasabah harus berhati-hati dengan tindak kejahatan melalui kegiatan hacker (Supriyono, 2011)

\section{c. Risiko Electronic Banking}

a) Card Skimming

Card skimming adalah tindakan menyalin (membaca dan menyimpan) informasi pada strip magnetis (garis lebar hitam) fungsinya untuk menyimpan data, nomor kartu, masa berlaku, dan nama nasabah. Card skimming dilakukan menggunakan alat pembaca kartu (card skimmer) yang ditempatkan pada kartu slot kartu di mesin ATM (Jasmi, 2015).

b) Card Trapping

Card trapping merupakan pengambilan fisik kartu dengan benda asing seperti, korek api, lidi, plastik, benang pada slot kartu mesin ATM. Dengan adanya tindak kejahatan tersebut nasabah akan kebingungan dan seolah-olah akan membantu nasabah untuk memasukkan nomor PIN dan sang pelaku akan memanfaatkan situasi tersebut, secara diam-diam pelaku kejahatan diam-diam mengintip nomor PIN nasabah (Ariyus, 2008).

c) Meminjamkan kartu dan PIN kepada orang lain

Nasabah harus memperlakukan kartu dan PIN sebagai sesuatu yang bersifat pribadi dan rahasia. Kartu dan PIN yang sudah diketahui oleh orang lain dapat disalah gunakan diluar pengetahuan si korban.

d) Social Engineering

Social engineering adalah upaya yang memanfaatkan pendekatan sosial untuk mendapatkan data rahasia nasabah atau meminta nasabah melakukan sesuatu yang 
menguntungkan pelaku, seperti transfer uang, pembayaran tagihan, dan pembelian pulsa.

e) Pencurian Data Kartu

Pencurian data kartu dapat dilakukan ketika petugas marketing palsu berhadapan dengan nasabah dengan mengunakan mesin ATM dan EDC palsu.

f) Penggunaaan Card Reader Illegal

Card Illegal adalah pencurian saldo pada kartu e-money melalui prses trapping yang dilakukan oleh oknum merchant yang menggunakan card reader mesin EDC yang bekerja dalam kondisi online maupun offline. Pelaku melakukan trapping kepada calon korban, atau dilakukan secara acak tanpa disadari oleh korban dengan tujuan mengurangi saldo yang ada dalam kartu e-money dalam jumlah tertentu sesuai dengan keinginan pelaku.

g) Gesek Tunai

Gesek tunai merupakan transaksi yang dapat dilakukan nasabah menggunakan kartu kredit pada merchant tertentu. Transaksi pembelian dengan merchant, akan tetapi nasabah tidak akan menerima barang atau jasa tetapi nasabah langsung memperoleh uang tunai dari merchant dengan fee yang dibebankan kepada merchant.

h) Phising

Phising merupakan tindakan yang dilakukan untuk mencari informasi rahasia dengan cara mengirimkan pesan palsu melalui komunikasi elektronik. Kebanyakan pelaku phising adalah kerjaan iseng yang tidak serius (Zam, 2014).

i) Man/Malware In The Browse (MIB)

MIB merupakan pembobolan internet banking dengan menggunakan software jahat yang terletak terhubung dengan browser internet nasabah.

j) Typosite

Typosite adalah halaman web yang alamatnya sama dengan web internet bank yang asli. Hal ini bertujuan untuk menjebak nasabah agar informasi yang dimiliki nasabah masuk pada halaman web yang palsu tersebut.

\subsection{Metode Penelitian}

Pendekatan penelitian yang digunakan dalam penelitian ini adalah pendekatan kualitatif. Pendekatan kualitatif adalah suatu kegiatan ilmiah yang dilakukan untuk menemukan dan mengembangkan serta menguji kebenaran suatu masalah atau pengetahuan guna mencari solusi atau pemecahan masalah tersebut (Rukin, 2019). Objek penelitian ini adalah di Koperasi Simpan Pinjam dan Pembiayaan Syariah (KSPPS) BMT Bina Ummat Sejahtera yang berada di Jl. Achmad Yani No. 4 Tayu, Pati, dengan focus pada pemanfaatan electronic banking yang meliputi pemanfaatan kartu ATM dan pengguna aplikasi mobile banking yang telah disediakan oleh pihak perbankan.

Subyek dalam penelitian ini meliputi karyawan ataupun anggota yang sudah menjadi anggota, mempunyai rekening dan sudah menggunakan aplikasi electronic banking yang ada di KSSPS BMT BUS seperti pemanfaatan ATM (Automatic Teller Machine) dan mobile banking.

Dalam penelitian ini, pengumpulan data diperoleh dari berbagai sumber, seperti pada kondisi yang alamiah (natural setting), sumber data primer, dan pengumpulan data yang bersifat observasi, wawancara mendalam (in depth interview) dan dokumentasi. Untuk membangun data yang terpercaya (valid), dilaukan teknik triangulasi (crossceck) serta diskusi dengan teman sejawat, serta pihak yang dianggap kompeten, seperti dosen dan peneliti. 


\section{HASIL DAN PEMBAHASAN}

\subsection{Pemanfaatan Electronic Banking Bagi Anggota di KSPPS BMT BUS Cabang Tayu}

Pemanfaatan electronic banking di BMT Bina Ummat Sejahtera, secara umum anggota masih memilih untuk menggunakan atau tidak menggunakan aplikasi tersebut. Sebagian anggota rata-rata belum bisa memenuhi persyaratan untuk menggunakan aplikasi terebut, seperti keterbatasan anggota dalam memiliki gadget dan kurang terpenuhinya sarana internet yang sewaktu-waktu bisa error dan menghambat pelayanan.

Meskipun, sebagian anggota lainnya bisa menerima dengan adanya aplikasi tersebut, karena bisa lebih mempermudah pelayanan tanpa harus datang langsung ke kantor cabang bank. Dengan demikian anggota bisa lebih memilih antara mau menggunakan atau tidak menggunakan aplikasi tersebut sesuai keinginan anggota itu sendiri. Namun, bagi pihak bank akan memberikan layanan tersebut karena itu adalah salah satu produk baru dari bank untuk bisa lebih meningkatkan layanan perbankan dengan adanya digital perbankan, agar kegiatan perbankan bisa lebih efektif dan efisien.

Sebelum adanya pemanfaatan electronic banking, pelayanan kepada anggota (Customer) dilakukan melalui kasir (teller) di kantor bank, dengan hal ini anggota tidak leluasa melakukan transaksi karena harus mengikuti jam kerja dari pukul 08.00-15.00 dan pada hari libur tidak dapat melakukan transaksi. Pelayanan tersebut mengakibatkan anggota tidak dapat menggunakan uangnya secara bebas sehingga cenderung menarik uang mereka di bank. Perilaku anggota tersebut berakibat pada lambatnya pertumbuhan jumlah anggota (permintaan).

Layanan electronic banking yang dilakukan melalui jalur online dapat memungkinkan nasabah untuk melakukan semua jenis transaksi melalui sarana internet. E-banking merupakan pelayanan jasa bank yang memungkinkan nasabah dapat memperoleh informasi, melakukan komunikasi dan transaksi melalui jaringan internet, dan tidak hanya menyelenggarakan layanan perbankan melalui jaringan internet saja.

Penggunaan layanan electronic banking di internet cukup mudah, seorang nasabah hanya dibekali dengan login dan kode akses ke situs web dimana terdapat fasilitas electronic banking yang bersangkutan. Untuk penggunaaan electronic banking dibutuhan keamanan transaksi, agar terhindar dari kegiatan orang yang tidak bertanggung jawab, maka sebuah situs web diwajibkan menggunakan standar keamanan yang sangat ketat untuk menjamin bahwa setiap layanan yang disediakan hanya dapat dimanfaatkan untuk mereka yang berhak.

Dari sinilah anggota di BMT BUS dapat memilih antara menggunakan atau tidak menggunakan layanan, dikarenakan mereka beranggapan bahwa hanya anggota kalangan menengah ataslah yang bisa menggunakan layanan ini. Hal ini karena mereka mempunyai fasilitas yang memadai seperti adanya HP dan sarana internet. Sedangkan dari anggota kalangan menengah bawah lebih tidak untuk menggunakan fasilitas yang disediakan oleh bank, karena terhalang oleh sarana dan prasarana yang kurang memadai.

Selain itu, sebagian anggota kurang memahami akan adanya layanan digital perbankan tersebut. Jika para anggota telah mempunyai sarana dan prasarana mereka juga akan eggan untuk mengunakan layanan yang ada di perbankan karena 
dipengaruhi adanya faktor dari usia yang sudah tidak muda lagi dan gagap akan teknolgi.

Dari sini, bias dipahami bahwa kecanggihan teknologi perbankan saat ini ternyata belum digunakan secara maksimal oleh para anggota BMT BUS, seperti adanya internet banking. Walaupun internet banking sudah ada sejak lama dan baru di terapkan di BMT BUS, ternyata para nasabah atau anggota cenderung enggan untuk menggunakan fasilitas internet banking tersebut. Mereka beranggapan bahwa dengan menggunakan internet banking itu sulit dan ribet, meskipun jika diikuti dengan baik, sebenarnya penggunaan internet banking ini sangatlah mudah.

\subsection{Analisis Faktor-Faktor Yang Mempengaruhi Electronic Banking Bagi Anggota}

Dengan memanfaatkan electronic banking, dapat memperoleh keuntungan yang dapat dilihat dari segi waktu dan tenaga yang dihemat. Karena electronic banking jelas bebas dari antrean dan dapat dilakukan di mana saja. Namun, secara factual, ada beberapa kendala dalam penggunaan e-banking ini.

1) Kemampuan dalam penggunaan teknologi

Kurangnya ilmu pengetahuan masyarakat tentang fasilitas electronic banking menyebabkan banyak yang belum mengerti dalam penggunaan teknologi (Gaptek). Dari hasil observasi yang dilakukan, sebagian anggota masih gaptek, seperti dua informan, yaitu ibu Ayuk dan ibu Sukinah. Hal ini dibuktikan pada Anggota sering bertanya kepada customer service karena ketidak-pahaman mereka dalam penggunaan aplikasi pada ponsel dan melakukan transaksi melalui ATM dan mobile banking sehingga para anggota masih saja memilih bertransaksi dengan cara mendatangi kantor cabang bank. Alasannya, mereka harus menggunakan ponsel pintar (gawai) yang menurut mereka cenderung ribet dan sulit dalam penggunaannya. Padahal sebenarnya mereka juga mempunyai gawai, dan bias mendukung fasilitas (fitur) layanan e-banking tersebut.

Anggota atau nasabah lebih memilih untuk melakukaukan aktivitas perbankannya secara manual yang harus face to face dengan teller karena mereka belum sepenuhnya memahami internet banking yang dirasa sangat sulit untuk menggunakannya. Mereka belum mengerti bahwa internet banking begitu banyak manfaatnya.

\section{2) Masalah Jaringan}

Anggota yang berada di daerah tertentu, sulit untuk mengakses jaringan, seperti mereka yang tinggal di daerah pedesaan. Ibu Sukinah yang tinggal di desa Langgeng Harjo, sulit untuk mengakses jaringan internet. Lokasi desa yang terletak di daerah pegunungan relatif sulit dijangkau jaringan, koneksi terganggu, sehingga internet akan melambat. Hal tersebut menjadi pertimbangan anggota, mereka lebih memilih untuk tidak menggunakan aplikasi tersebut.

Penerapan electronic banking terhadap anggota atau nasabah tidak selalu berjalan dengan baik. Tentunya kegiatan dalam layanan electronic banking pasti terdapat faktor yang mempengaruhi anggota dalam memanfaatkan electronic banking. Faktor tersebut merupakan hal-hal yang mempengaruhi keberhasilan pelaksanaan layanan yang menjadikan lembaga lebih berkembang dan menjadi lebih baik lagi.

a. Minat Anggota

Faktor minat Anggota dalam menggunakan electronic banking adalah rasa ketertarikan pada suatu hal atau aktivitas tanpa ada paksaan dan merasa senang untuk 
mempelajarinya. Rasa ketertarikan tersebut bukan karena paksaan tapi kesadaran yang tinggi karena keinginan yang kuat untuk mencapai tujuannya (Al Bayan, 2015). Minat merupakan salah satu faktor yang sangat mempengaruhi anggotanya untuk menggunakan fasilitas $e$-banking yang telah disediakan oleh perbankan.

b. Kepercayaan Anggota

Faktor kepercayaan juga mempengaruhi anggota dalam memanfaatkan electronic banking. Kepercayaan merupakan kemauan seseorang untuk peka terhadap tindakan orang lain berdasarkan pada harapan (Damsar dan Indrayani, 2018). Hal tersebut membuktikan manfaat yang diperoleh dari electronic banking tidak dipengaruhi oleh kepercayaan seseorang terhadap electronic banking. Dengan kata lain, belum tentu seseorang akan menganggap electronic banking itu bermanfaat meskipun kepercayaan electronic banking tersebut tinggi dan pulsa atau kuota juga akan menjadi salah satu kendala dalam menggunakan electronic banking tersebut.

Kepercayaan nasabah merupakan faktor penting yang mendorong nasabah untuk bertransaksi perbankan, apakah nasabah mau untuk menggunakan atau tidak menggunakan electronic banking yang telah disediakan pihak bank. Oleh karena itu semakin tinggi tingkat kepercayaan anggota terhadap electronic banking, maka anggota akan semakin merasakan manfaat dari electronic banking tersebut, dan begitu pula sebaliknya.

c. Persepsi manfaat

Persepsi manfaaat merupakan yang mana seseorang mempercayai dan merasakan manfaat yang timbul dari menggunakan suatu teknologi (Permana dan Astuti, 2012). ATM dan Mobile banking memiliki begitu banyak Keunggulan dan manfaat yang secara keseluruhan membantu anggota perbankan agar dapat melakukan transaksi kapan saja dan dimana saja.

Namun, sebagian besar anggota perbankan masih belum menggunakan layanan tersebut dan tidak sedikit dari mereka yang masih memilih menggunakan ATM atau datang langsung ke kantor cabang perbankan daripada menggunakan aplikasi mobile banking dalam melakukan transaksi maupun hanya sekedar memperoleh informasi mengenai saldo perbankannya meskipun hal tersebut memakan lebih banyak waktu dan tenaga. Faktor inilah yang mempengaruhi penerimaan penggunaan $e$-banking yang mana anggota belum sepenuhnya memahami e-banking bahwa manfaatnya besar tetapi mereka memiliki akun e-banking lain yang lebih bagus aksesnya. Hal tersebut dapat terjadi karena responden menganggap bahwa manfaat yang diberikan oleh electronic banking belum sepenuhnya dapat di terima oleh anggota BMT BUS.

d. Persepsi kemudahan

Persepsi kemudahan penggunaan merupakan sejauh mana seseorang percaya bahwa dalam menggunakan suatu teknologi tertentu tidak memerlukan usaha yang besar, hemat biaya, dan watu sehingga memudahkan aktivitas penggunanya. Factor kemudahan ini yang mendorong anggota untuk menggunakan jasa layanan mobile banking.

Para anggota pengguna mobile banking mengatakan bahwa penggunaan mobile banking sanggatlah mempermudah dan memberikan keleluasaan dalam kegiatan transaksi keuangan misalnya untuk mengecek informasi saldo tabungan, pembayaran tagihan (listrik, air, dsb), transaksi pembelian (voucher HP, PLN), transaksi transfer uang sehingga layanan lainnya dalam satu sentuhan dilayar telepon seluler tanpa harus menghabiskan waktu untuk pergi ke ATM atau kantor-kantor cabang terdekat. Selain mempermudah transaksi keuangan, cara pengoperasiannya pun begitu mudah sehingga semua orang bisa menggunakannya. Oleh karena itu, semakin tinggi tingkat 
usia maka semakin sukar dalam beradaptasi terhadap teknologi baru. Sebaliknya, semakin muda usia seseorang semakin mudah melakukan adopsi dan adaptasi terhadap teknologi.

e. Persepsi resiko

Faktor resiko yang dapat diartikan sebagai pandangan seseorang akan ketidak pastian dan konsekuensi negatif yang mungkin terjadi dari penggunaan suatu sistem tertentu. Salah satu resiko terbesar penggunaan e-banking adalah ancaman hacker dengan sistem proteksi yang memadai dan berlapis, bank-bank terancam karena anggota akan enggan melakukan transaksi melalui $e$-banking.

Akan tetapi penggunaan e-banking juga semakin mudah di pahami dengan adanya kemudahan akses informasi melalui internet tentang penyalahgunaan layanan perbankan seperti cracking, skimming, dan hacking melalui ATM, kartu kredit, dan lain sebagainya. Ada banyak resiko yang akan dihadapi oleh anggota dalam menggunakan fasilitas electronic banking, baik itu resiko keamanan internal seperti kegagalan sistem maupun resiko eksternal seperti serangan hacker maupun resiko lainnya seperti resiko confidential atau jaminan kerahasiaan dan jaminan keamanan bertransaksi, yang mana kebanyakan anggotanya rata-rata telah berusia lanjut yang memiliki pola pikir yang berbeda dengan anggota yang dewasa dari segi risiko.

Dengan memberikan adanya layanan electronic banking dapat meningkatkan kemauan nasabah atau anggota dalam menggunakan electronic banking yang mudah tanpa harus datang ke kantor untuk melakukan transaksi keuangannya. Sebenarnya electronic banking ini cocok digunakan untuk anggota yang memiliki tingkat kegiatan atau kesibukan yang padat, karena eletronic banking bisa menjadi alternatif agar bisa bertransaksi kapanpun dan dimanapun anggota berada tanpa harus datang ke bank.

\section{PENUTUP}

Pemanfaatan Electronic di BMT Bina Ummat Sejahtera saat ini anggota masih memilih untuk menggunakan atau tidak menggunakan aplikasi tersebut. Sebagian anggotanya rata-rata belum bisa memenuhi persyaratan, seperti keterbatasan anggota dalam memiliki gadget, gagap teknologi (gaptek), dan kurang terpenuhinya sarana internet yang sewaktu-waktu bisa error dan menghambat pelayanan.

Faktor yang dapat mempengaruhi anggota dalam menggunakan electronic banking yaitu dari segi minat, kepercayaan, maupun dari segi persepsi manfaat, kemudahan penggunaan dan persepsi resiko terhadap pemanfaatan electronic banking bagi anggota di BMT BUS. Sebagian anggota belum bisa menggunakan komputer/gadged dan tidak memiliki kepercayaan terhadap layanan electronic banking, sehingga memungkinkan untuk tidak menggunakan electronic banking tersebut. Salah satu kendalanya adalah keterbatasan sarana dan prasarana electronic banking, terlebih bagi anggota yang sudah lanjut usia. Jadi bagi anggota di BMT Bina Ummat Sejahtera saat ini sebagian anggotanya sudah menggunakan aplikasi electronic banking dan sebagian lagi belum menggunakan aplikasi electronic banking. 


\section{DAFTAR PUSTAKA}

Al-Bayan, Zhanta. 2015. Muda Berkarya.Jakarta: PT Elex Media Komputindo.

Ariyus, Dony. 2008. Pengantar Ilmu Kriptografi Teori, Analisis, dan Implementasi.Yogyakarta: CV. Andi Offset.

Damsar dan Indrayani. 2018. Pengantar Sosiologi Pasar. Jakarta: Prenadmedia Group.

Hambali, Fitriansyah, dkk. Analisis Technologi Model (TAM) terhadap Faktor-Faktor yang Mempengaruhi Penerimaan Nasabah terhadap Layanan Internet Banking. Jurnal Proceding PESAT (Psikologi, Ekonomi, Sastra, Arsitektur dan Sipil) vol.4 (2014), ISSN: 1858-2559.

Hamidin, Asep S. 2010. Tips dan Trik Kartu Kredit Memaksimalkan Manfaat \& Mengelola Risiko Kartu Kredit.Yogyakarta: Media Persindo.

Jasmi dkk. 2015. Bijak Ber-Electronic Banking. Jakarta: Otoritas Jasa Keuangan.

Joyosumarto,Subarjo. 2018. BANKIR: Kepemimpinan Lembaga Perbankan Abad ke-21. Jakarta: PT Elex Media Komputindo.

Juanda, Ebit. 2018. Tujuh Cara Cepat Pintar Komputer. Jakarta.

Lestari, Rizki Nanda. 2019. Kepuasan Nasabah pada Electronic Banking CIMB Niaga. Surabaya: Sekolah Tinggi Ilmu Ekonomi, Artikel Ilmiah,.

Permana, Widia dan Astuti, Endang Siti. 2012. Layanan Kepustakaan Via Mobile Data (Malang: Elektronik Permata dan Terbesar di Indonesia.

Pinontoan,Wulan, Pengaruh E-Banking, Kualitas Pelayanan, Kualitas Komunikasi dan Kepercayaan terhadap Loyalitas Nasabah pada PT. Bank Mandiri Cabang Manado," Jurnal Emba vol.1 no. 4 (2013)

Rukin. 2019. Metodologi Penelitian Kualitatif. Sulawesi Selatan: Yayasan Ahmar Cendekia Indonesia.

Supriyono, Maryanto. 2011. Buku Pintar Perbankan. Yogyakarta: C.V Andi Offset.

Zam, Efvy. 2014. Phishing: Cara Mudah Menyadap Password dan Pencegahannya. Jakarta Selatan: PT. TransMedia. 